\title{
Gold nanoparticle-decorated reduced-graphene oxide targeting anti hepatitis B virus core antigen
}

\begin{abstract}
Hepatitis B virus core antigen ( $\mathrm{HBcAg}$ ) is the major structural protein of hepatitis B virus (HBV). The presence of anti-HBcAg antibody in a blood serum indicates that a person has been exposed to HBV. This study demonstrated that the immobilization of $\mathrm{HBcAg}$ onto the gold nanoparticles-decorated reduced graphene oxide (rGO-enAuNPs) nanocomposite could be used as an antigen-functionalized surface to sense the presence of anti-HBcAg. The modified rGO-en-AuNPs/HBcAg was then allowed to undergo impedimetric detection of anti-HBcAg with anti-estradiol antibody and bovine serum albumin as the interferences. Upon successful detection of anti-HBcAg in spiked buffer samples, impedimetric detection of the antibody was then further carried out in spiked human serum samples. The electrochemical response showed a linear relationship between electron transfer resistance and the concentration of anti$\mathrm{HBcAg}$ ranging from $3.91 \mathrm{ng} \mathrm{mL}-1$ to $125.00 \mathrm{ng} \mathrm{mL}-1$ with lowest limit of detection (LOD) of $3.80 \mathrm{ng} \mathrm{mL}-1$ at $3 \sigma \mathrm{m}-1$. This established method exhibits potential as a fast and convenient way to detect anti-HBcAg.
\end{abstract}

Keyword: Hepatitis B virus; Antibody; Impedimetric biosensor; Reduced graphene oxide; Gold nanoparticles 
